\title{
SPEED AND PARAMETER IDENTIFICATION FOR SENSORLESS VECTOR CONTROL OF INDUCTION MOTORS AT VERY LOW SPEED
}

\author{
Yehia S. Mohamed \\ Electrical Engineering Department, Faculty of Engineering, Minia \\ University, Minia, Egypt.
}

(Received September 14, 2005 Accepted November 7, 2005)

\begin{abstract}
A novel sensorless vector controlled induction motor drive system is presented in this paper. In this system, compensation of the drift components of the stator voltage vector is done by offset voltage vector estimation to improve the low-speed drive characteristics. The motor speed is estimated from the difference between the estimated synchronous and slip speed. An effective on-line method for estimating both stator and rotor resistances is introduced in this system to achieve high-precision control at low-speed. The estimation method for rotor resistance is based on the error signal between the command value of reactive power and its actual value being based on stator voltage and current measurements. On the other hand, the error between the magnitude of the stator current command and its measured value is used to estimate the stator resistance variations from its set value. This paper clarifies that the low-speed estimation is possible with stator and rotor resistance estimation and the zero-speed control is achieved under load condition. Simulation results are provided to demonstrate smooth steady-state operation and high dynamic performance of the drive system at very low-speed and at zerospeed.
\end{abstract}

\section{LIST OF SYMBOLS}

$\begin{array}{ll}V, i & \text { instantaneous value of voltage and current, respectively. } \\ i_{s} & \text { stator current phasor magnitude } \\ L_{s}, L_{r} & \text { stator and rotor self-inductances respectively. } \\ L_{m} & \text { static magnetizing inductance. } \\ n & \text { number of sampls } \\ P & \text { number of pole pairs } \\ Q & \text { reactive power } \\ R_{s}, R_{r} & \text { stator and rotor resistances } \\ t & \text { time } \\ \omega_{r} & \text { electrical rotor angular velocity } \\ \omega_{s l} & \text { electrical slip angular velocity }\end{array}$




$\begin{array}{ll}\omega_{s} & \text { electrical stator angular velocity } \\ \theta_{s} & \text { field angle } \\ \psi_{r n} & \text { rated value of rotor flux linkage. }\end{array}$

SUBSCRIPTS

$\begin{array}{ll}d-q & \text { direct and quadrature axis } \\ \alpha-\beta & \text { stationary reference frame } \\ s, r & \text { stator and rotor, respectively } \\ * & \text { denote the reference value } \\ \wedge & \text { denote the estimated value }\end{array}$

\section{INTRODUCTION}

Vector controlled induction motor drive has been widely used in various industrial fields. Recently, the sensorless vector control is much more focused and has progressed due to some of its advantages, such as mechanical robustness, simple construction and free maintenance [1]-[5]. However, the speed-sensorless operation, especially in the very low-speed region is very difficult. The main reasons are noise, offset and drift components in the acquired voltage signals, its limited band width and the increased sensitivity against model parameter mismatch.

When a voltage source inverter (VSI) is used to feed the machine, the stator voltages are formed by pulse trains having a typical rise time of $2-5 \mathrm{kV} / \mu \mathrm{s}$. These are digitally acquired at a high, though limited sampling rate. The limited bandwidth of such sampling process may fail to establish the exact volt-second equivalent between the actual and the acquired signals, and hence produce an error. To avoid this complication, some authors have used a current source inverter (CSI) [6], or a linear power amplifier [7], to make use of smooth voltage waveforms that can be accurately acquired even at limited sampling rate.

The indirect vector control drives are based on the slip-frequency, this control calculation is strongly influenced by the rotor resistance variation because rotor resistance is used for the speed estimation. Also, the stator resistance variation influences the speed estimation because the flux estimation uses stator circuit resistance and voltages. These deficiencies deteriorate the dynamic performance of drives at low speed. Sustained operation at very low speed becomes impossible as ripple components appear in the motor torque and the speed starts oscillating, eventually leading to unstable operation of the drive system. To overcome these problems and to achieve good steady-state and dynamic performance at very low speed the stator and rotor resistances estimation and the stator voltage signals compensation are required.

There are many techniques for online identification of motor parameters [8][11]. Most of these techniques need motor speed information and hence, cannot be used for induction motors without rotational transducers. Since it is difficult to identify 
the rotor resistance without motor speed information and it is impossible to estimate the rotor resistance and motor speed simultaneously under the field oriented control if the rotor flux is completely constant [12]. To avoid this problem, there are several methods for the rotor resistance estimation in the speed sensorless control. In [13] and [14] it was estimated from the higher order harmonics of the rotor slots, but it is difficult to estimate the rotor resistance in the low-speed region because it becomes difficult to measure the higher order harmonics in the low-speed region.

In [15] the rotor resistance was estimated by adding the small alternating current to the rotor flux so that it is fluctuated, but this causes the ripple of the torque and the real speed oscillation. Viewing the recent literature, the stator resistance is determined in [16] as the small difference between two large quantities, namely real stator power and air-gap power and as such the result is prone to error. In [17] an artificial neural network (ANN) is employed to identify changes to stator resistance explicity and tune a model-based speed sensorless control system. The ANN is trained off-line by putting the drive through a cycle of speed and load changes, measuring stator resistance at regular periods. The method overcomes the well-known low speed limitations of conventional methods based on ideal motor model, yet without relying on a more detailed motor model or parasitic effects [18]. In this method, the ideal motor model is augmented with mechanical dynamics to overcome the low speed limitations. The response of the electromechanical system to a low-frequency ac current signal injected in to the stator winding depends on the direction of the signal relative to the rotor flux angle direction. Based on this dependency, a new algorithm for rotor flux angle estimation, applicable when the total moment of inertia is not too high, is developed.

In spite of these efforts, the low-speed operation of sensorless drive of the induction motor still remains an unsolved problem.

In this paper, a novel sensorless vector controlled induction motor drive system is presented. In this system, compensation of the drift components of the stator voltage vector is done by offset voltage vector estimation to improve the low-speed drive performance. The motor speed is estimated based on the difference between the estimated synchronous and slip speed. This system includes also, an effective on-line method for estimating both stator and rotor circuit resistances to achieve highprecision control at low-speed. The estimation method for both stator and rotor resistances use only the stator voltage and current measurements. The estimation method for rotor circuit resistance is based on the error signal between the command value of reactive power and its actual value. On the other hand, the error between the magnitude of the stator current command and its measured value is used to estimate the stator circuit resistance variations from its set value. This paper clarifies that the low-speed estimation is possible with stator and rotor resistance estimation and the zero-speed control is achieved under full-load condition. Simulation results are presented to demonstrate that the proposed sensorless drive system is capable of working at very low-speed and exhibits very good dynamic and steady-state performance. 


\section{MOTOR SPEED ESTIMATION ALGORITHM}

In order to obtain an accurate dynamic representation of the motor speed, it is necessary to base the estimation speed on the coupled nonlinear circuit equations of motor. The stator flux linkage components and their derivatives are widely known from the voltage model of the fundamental equation of induction motor in the stationary reference frame $(\alpha-\beta)[5]$ :

$$
\begin{aligned}
& \psi_{\alpha s}=\int\left(V_{\alpha s}-i_{\alpha s} R_{s}\right) d t \\
& \psi_{\beta s}=\int\left(V_{\beta s}-i_{\beta s} R_{s}\right) d t
\end{aligned}
$$

The estimation of the stator flux components according to (1) require performing an integration in real-time of the induced voltage components. However, this estimation scheme is not robust due to stator resistance variation, offsets and initial conditions of the system drift. These problems are especially important at low speed. The use of a pure integrator has not been reported in the literature. The reason is that an integrator has an infinite gain at zero frequency. The unavoidable offsets contained in the integrator input then make its output gradually drift away beyond limits. Therefore, instead of an integrator a low pass filter that usually serves a substitute and improved scheme has to be used. In this scheme, the estimated stator voltage vector components $\left(\hat{U}_{\alpha s}\right.$ and $\left.\hat{U}_{\beta s}\right)$ are introduced for compensating all disturbances produced from offsets and other errors resulting from either the voltage signal or from current signal. This yields, the estimated stator flux components as:

$$
\begin{aligned}
& \hat{\psi}_{\alpha s}=\int\left(V_{\alpha s}-i_{\alpha s} R_{s}+\hat{U}_{\alpha s}\right) d t \\
& \hat{\psi}_{\beta s}=\int\left(V_{\beta s}-i_{\beta s} R_{s}+\hat{U}_{\beta s}\right) d t
\end{aligned}
$$

The estimated stator voltage vector components are given as:

$$
\begin{aligned}
& \hat{U}_{\alpha s}=k\left(\psi^{*}{ }_{\alpha s}-\hat{\psi}_{\alpha s}\right) e^{j \theta_{s}} \\
& \hat{U}_{\beta s}=k\left(\psi^{*}{ }_{\beta s}-\hat{\psi}_{\beta s}\right) e^{j \theta_{s}}
\end{aligned}
$$

The estimated stator voltage components are determined such that the estimated stator flux components rotate close to a circular trajectory in the steadystate, which follows from (2) and from the right hand side of (3). The gain constant $k$ in equation (3) is chosen such that the disturbances introduced by offsets and other errors are compensated. A major source of error in the stator flux estimator (equation (2)) is the model parameter of the machine. To overcome this error, a compensator has been designed and explained for estimating the stator resistance in the next section.

The angle of the stator flux vector is defined as:

$$
\hat{\theta}_{s}=\tan ^{-1}\left(\frac{\hat{\psi}_{\beta s}}{\hat{\psi}_{\alpha s}}\right)
$$


If differentiation is performed analytically in equation (4), the estimated stator angular frequency is obtained as:

$$
\hat{\omega}_{s}=\frac{d \hat{\theta}_{s}}{d t}=\frac{\hat{\psi}_{\alpha s} \dot{\hat{\psi}}_{\beta s}-\hat{\psi}_{\beta s} \dot{\hat{\psi}}_{\alpha s}}{\hat{\psi}_{\alpha s}^{2}+\hat{\psi}_{\beta s}^{2}}
$$

The estimated value of motor speed $\hat{\omega}_{r}$ can be calculated from the difference between the estimated synchronous and slip speeds as:

$$
\hat{\omega}_{r}=\frac{\hat{\omega}_{s}}{P}-\hat{\omega}_{s l}
$$

Where the estimated slip speed $\hat{\omega}_{s l}$ is directly obtained from the command torque and flux values as:

$$
\hat{\omega}_{s l}=\frac{3 R_{r}}{2 P} \frac{\hat{T}_{e}^{*}}{\psi^{* 2}{ }^{2}}
$$

From equation (7) it is clear that, the rotor resistance variation has a strong influence upon the speed estimation. At very low-speeds and the load over $25 \%$, the rotor resistance is changed by the heating. Therefore, a rotor resistance estimation algorithm is introduced in this paper to compensate this thermal variation in the rotor resistance.

\section{EFFECT OF STATOR RESISTANCE VARIATION AND ITS COMPENSATION}

The stator resistance changes due to change in temperature during the operation of the machine as the machine losses change. The variation of the stator resistance is a thermal process and therefore is not only determined by the machine losses but also by the time. In vector control drive, the stator flux is estimated by integrating the difference between the stator voltage and the resistive voltage drop across the stator winding of the machine. Among the other variables of the machine, the stator flux vector is highly affected by the resistance changes especially at low speed.

Using the inherent good low-speed performance of the compensated flux estimator (equation (2)) requires the accurate on-line estimation of the stator resistance, which is the relevant parameter of the machine model. An estimator has been designed to estimate the change in stator resistance of the motor. This estimator is based on the principle that the change in stator resistance is proportional to the error between the measured stator current phasor magnitude and its command [19]. The stator feedback current phasor magnitude $i_{s}$ is obtained from the $\alpha$ and $\beta$ axis measured currents as:

$$
i_{s}=\sqrt{i_{\alpha s}^{2}+i_{\beta s}^{2}}
$$


The stator command current phasor magnitude $i^{*}$ is derived from the dynamic equations of the induction motor in the synchronously rotating reference frame using the torque and rotor flux linkage commands as:

$$
i^{*}{ }_{s}=\sqrt{i^{*}{ }^{2}{ }^{2}+i_{q s}^{*}}
$$

The incremental value of stator resistance is obtained through a PI controller. The PI stator resistance compensator can be expressed in the z-transform as follows:

$$
\Delta R_{s}=\left(K_{p}+\frac{T z}{z-1} K_{i}\right) \Delta i_{s}
$$

Where $T$ is the sampling time, $z=e^{j \omega_{s} T}, K_{p}$ and $K_{i}$ are the proportional and integral gains of the PI compensator and $\Delta R_{s}$ is the change value in the stator resistance. The current error $\Delta i_{s}$ is passed through a low pass filter with a very low cutoff frequency in order to attenuate high frequency components contained in the stator current measurement. Then, the current error signal is applied to a PI compensator. The output of the PI compensator is the required change of stator resistance $\Delta R_{s}$ which is mainly caused by the motor temperature variation and to a smaller change by the varying stator frequency. The estimated stator resistance $\hat{R}_{s}(n-1)$ is continuously added to the previously estimated stator resistance to update the estimated value (where $n$ is the nnmber of sampls).

\section{ROTOR RESISTANCE ESTIMATION FOR THE LOW-SPEED REGION}

To allow correct estimation and consequently proper operation of the sensorless control at low-speed region, it is required to estimate the rotor resistance value. The rotor resistance variation is estimated based on the error signal between the command and the estimated reactive powers and then modification of the rotor resistance applicable in the sensorless indirect vector control system. The command reactive power $Q^{*}$ is calculated based on the stator current components in the synchronous reference frame $(d q)$ as :

$$
Q^{*}=\omega_{s}\left(L_{s} i^{*^{2}} d s+L_{\sigma} i_{q s}^{*^{2}}\right)
$$

Where

$L_{\sigma}=L_{s}-\frac{L_{m}^{2}}{L_{r}}, i^{*}{ }_{d s}$ and $i^{*}$ qs are $d$ and $q$ components of stator current command

The actual reactive power $Q$ can be estimated in terms of the stator current and voltage components in the stationary reference frame $(\alpha-\beta)$

$$
\hat{Q}=V_{\beta s} i_{\alpha s}-V_{\alpha s} i_{\beta s}
$$


The error signal $\Delta Q$ between the command $Q^{*}$ and the estimated $\hat{Q}$ values is converted to the rotor resistance variation $\Delta R_{r}$ through PID controller as follows:

$$
\Delta R_{r}=\left(K_{P}+\frac{T Z}{Z-1} K_{I}+\frac{T(Z-1)}{Z} K_{D}\right) \Delta Q
$$

Where $K_{P}, K_{I}$ and $K_{D}$ are the coefficients of proportional, integral and derivative of PID controller.

The rotor resistance is iteratively updated as:

$$
\hat{R}_{r}(n)=\hat{R}_{r}(n-1)+\Delta R_{r}
$$

The updated rotor resistance values tends to its actual when $\Delta Q$ becomes zero.

\section{PROPOSED SENSORLESS INDUCTION MOTOR DRIVE}

Figure 1 shows the block diagram of the proposed sensorless indirect vector controlled induction motor drive system. The control system consists of a speed controller, two current controllers, coordinate transformation (CT), a digital pulse width modulation (PWM) scheme for a transistor bridge inverter, stator flux estimator, slip speed calculator, stator and rotor resistance compensators and motor speed estimator. The speed controller is a classical proportional plus integral (PI) regulator which produces the command q-component of stator current from the speed difference between the command speed and the estimated motor speed. The two current controllers of Fig. 1 are included for controlling the torque producing currentcomponent and the magnetizing current-component. Since the quantities to be adjusted by these current controllers are dc quantities, a classical PI (proportional-integral) control technique can be successfully employed. The output of these controllers are the $d$-axis and $q$-axis component of stator voltage commands. The coordinate transformation (CT) in Fig. 1 is used for transforming these components to the threephase stator voltage commands by using the field angle. Measurements of two stator phase voltages and currents are transformed to $\alpha$ - and $\beta$ - components and used in the stator flux estimator, stator and rotor resistance compensators and the indirect vector control. The rotor flux command value $\psi^{*}{ }^{*}$ is chosen as a constant value in this paper equal to its rated value $\psi_{r n}$. The estimated stator flux components are used to estimate the motor speed at low speed range. This speed is used as the feedback signal in the outer speed loop and in the orienting of the injected stator current vector for torque and flux control. The estimated rotor circuit resistance is used in the slip speed calculator and the estimated stator circuit resistance is used in the stator flux estimator.

The method uses stator reference frame model of the induction motor and the same reference frame is used in the implementation thereby avoiding the trigonometric operations encountered in the CT of other reference frames. This is one of the advantages of the control scheme. 


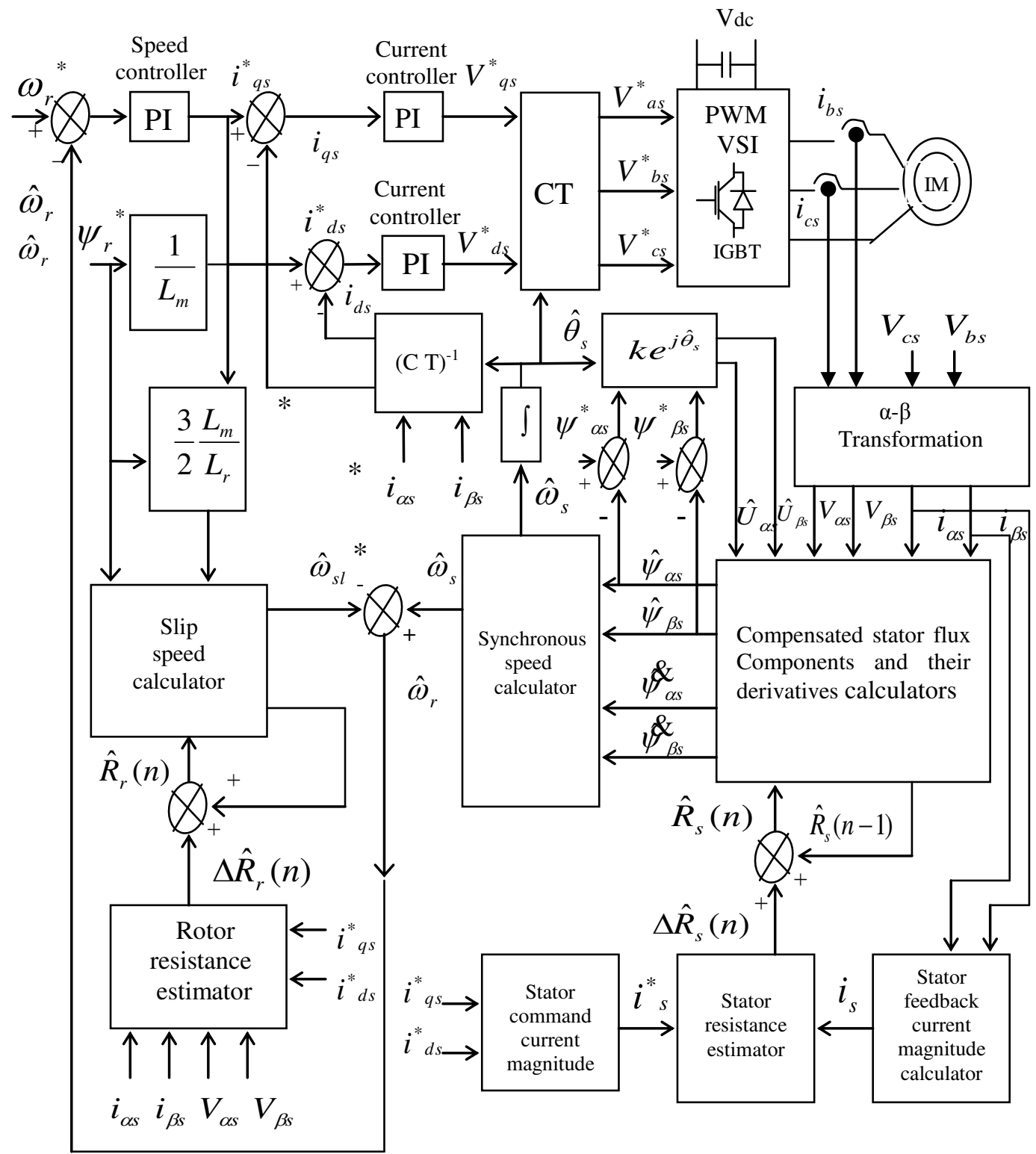

Figure 1: Block diagram of the proposed sensorless induction motor drive $\psi^{*}{ }_{r}=\psi_{r n}$.

\section{RESULTS AND DISCUSSION}

The proposed sensorless induction motor drive of Fig. 1 is verified using simulations. The induction motor under study is a $3 \mathrm{~kW}$, four-pole motor, the motor parameters and specifications are listed in Table 1: 
Table 1: Simulation machine parameters.

\begin{tabular}{|l|c|c|c|}
\hline Poles & 4 & fsynchronous & $50 \mathrm{~Hz}$ \\
\hline$P$ machine & $3 \mathrm{~kW}$ & $V$ line, Iline & $380 \mathrm{~V}, 6.4 \mathrm{~A}$ \\
\hline$R s$ & $2.15 \Omega$ & $R r$ & $2.33 \Omega$ \\
\hline$L s, L r$ & $210 \mathrm{mH}$ & $L m=202.5 \mathrm{mH}$ & $J m=0.008 \mathrm{~kg} \mathrm{~m}^{2}$ \\
\hline
\end{tabular}

The PI controller is tuned as to give satisfactory speed response when parameter errors are absent.

Dynamic operation at very low speeds is demonstrated by Fig. 2 showing a reversal of speed from $+10 \mathrm{rpm}$ to $-10 \mathrm{rpm}$ under no-load condition. Figure 2 shows that the proposed sensorless drive exhibits excellent dynamic performance during speed transient operation. The estimated stator flux linkage vectors exhibit sinusoidal waveforms without offset, drift or distortion and smooth operation is achieved. In lower graph of Fig. 2 the stator current during the speed transient operation is depicted.

The transient performance of the proposed sensorless drive system is studied for step-change of the load torque. Figure 3 shows the calculated field angle, motor speed, torque, stator current and flux components responses when the motor is subjected to $20 \mathrm{~N} . \mathrm{m}$ (about rated torque) step-change of load torque at 10 r.p.m. Only a short time after the application and removal of the load torque, the proposed sensorless drive system exhibits a small and fast decreasing speed estimation error. Figure 3 shows also, fast and good response of the motor torque. However, this torque exhibits high-frequency pulsations of large magnitude due to voltage source inverter pulse width modulation.

It is worthy to mention that the value of stator current components match the value of load torque provided that the stator flux components are kept constant during the change of load torque as shown in Fig. 3.

The transient performance of the proposed sensorless drive system is investigated for zero-speed control under nominal load torque. Figure 4 shows the calculated field angle, motor speed, torque, stator current and flux components responses for an acceleration to 20 r.p.m followed by a decleration to zero-speed and an acceleration again to 20 r.p.m under about $100 \%$ load. From Fig. 4 the proposed sensorless drive has good and stable performance during zero-speed control under rated load torque. The connection of the load to the motor ensures correct speed estimation during transient operation due to high inertia of the drive.

Finally, the performance of the stator and rotor resistance estimations scheme is demonstrated in Fig. 5. The stator and rotor resistances are increased by $50 \%$ in step change fashion. The disturbance causes a sudden deviation from the correct field angle, which produces wrong values in the motor torque and speed. The new values of stator and rotor resistances are estimated after a short delay and the motor torque and speed readjusts to their original level. 


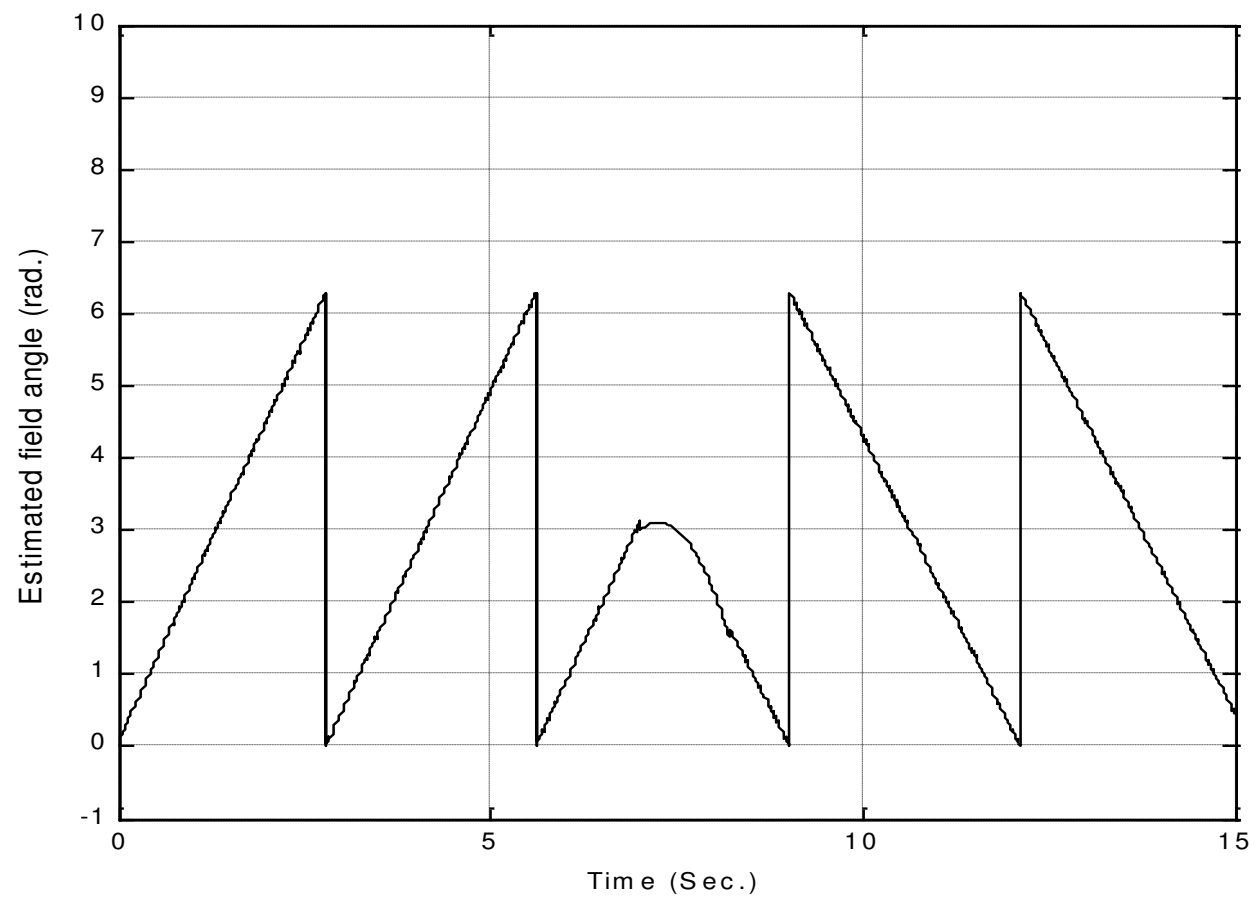

(a)

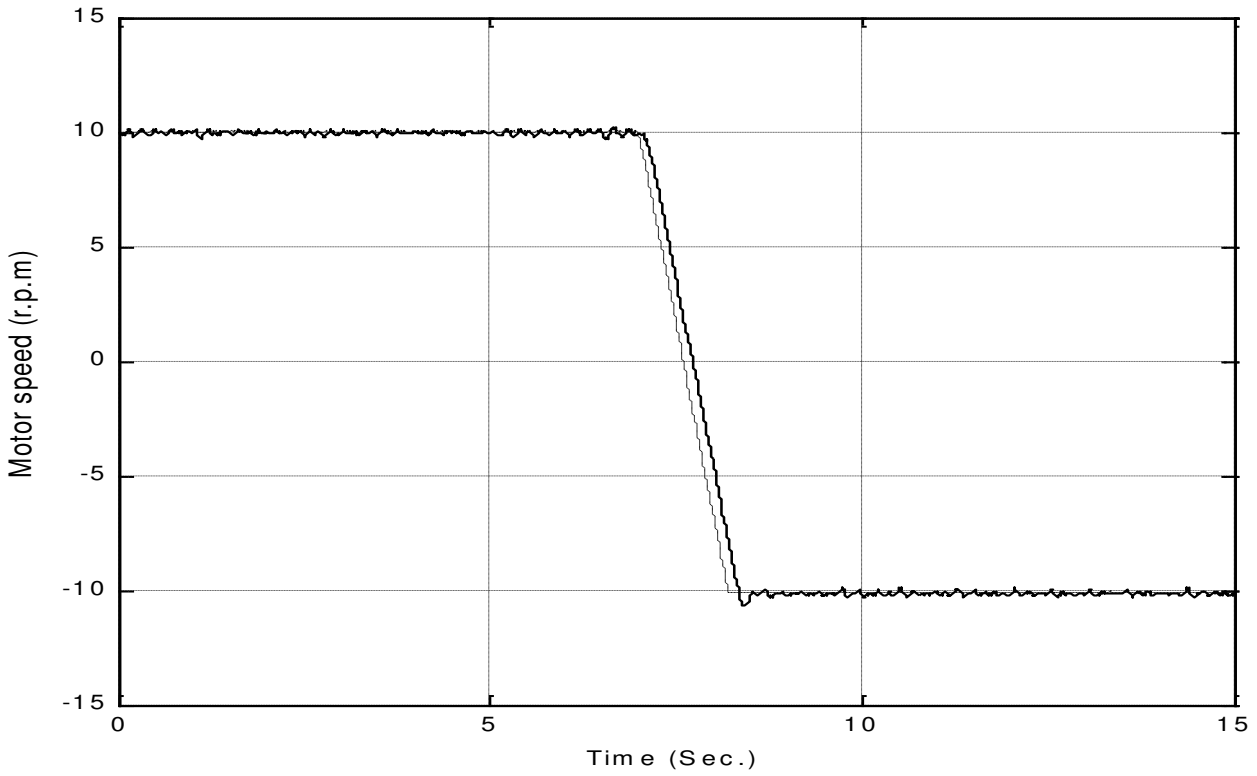

(b) 


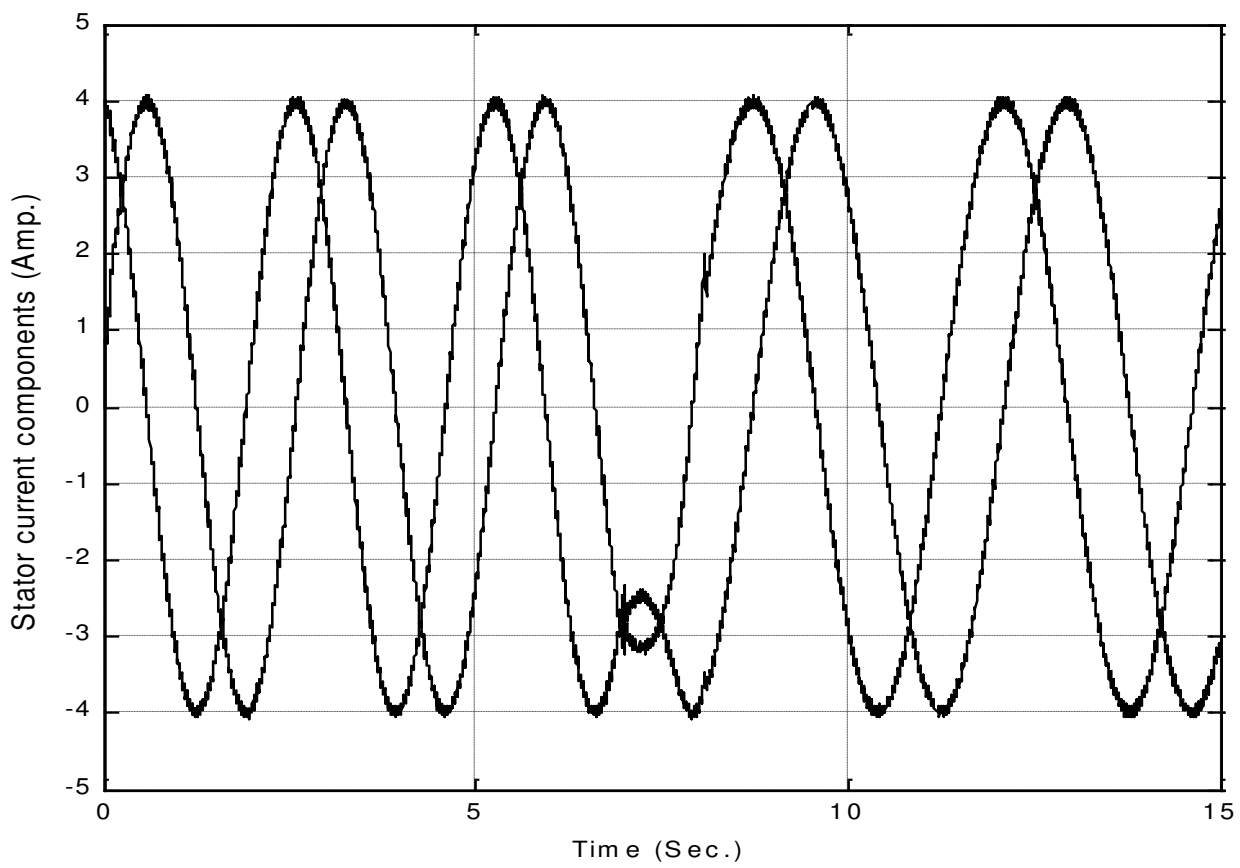

(c)

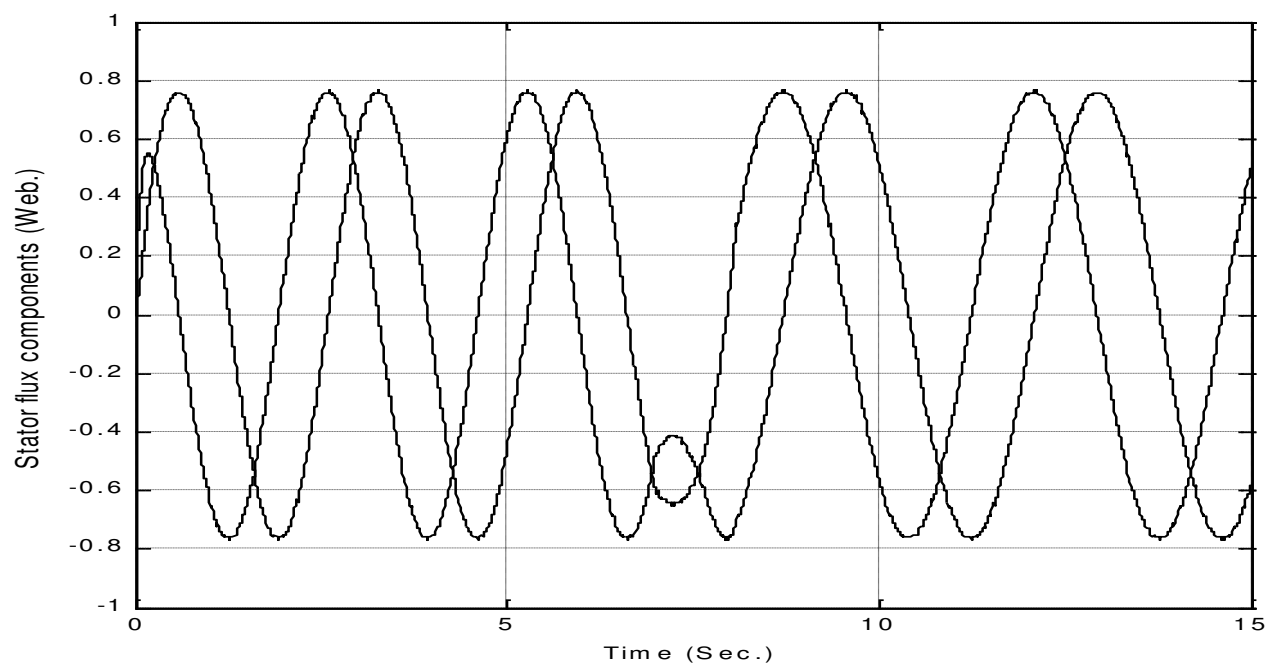

(d)

Figure 2: Simulation results of the speed reversal operation using the proposed sensorless.
(a) estimated field angle
(b) motor speed
(c) stator current components
(d) stator flux components 


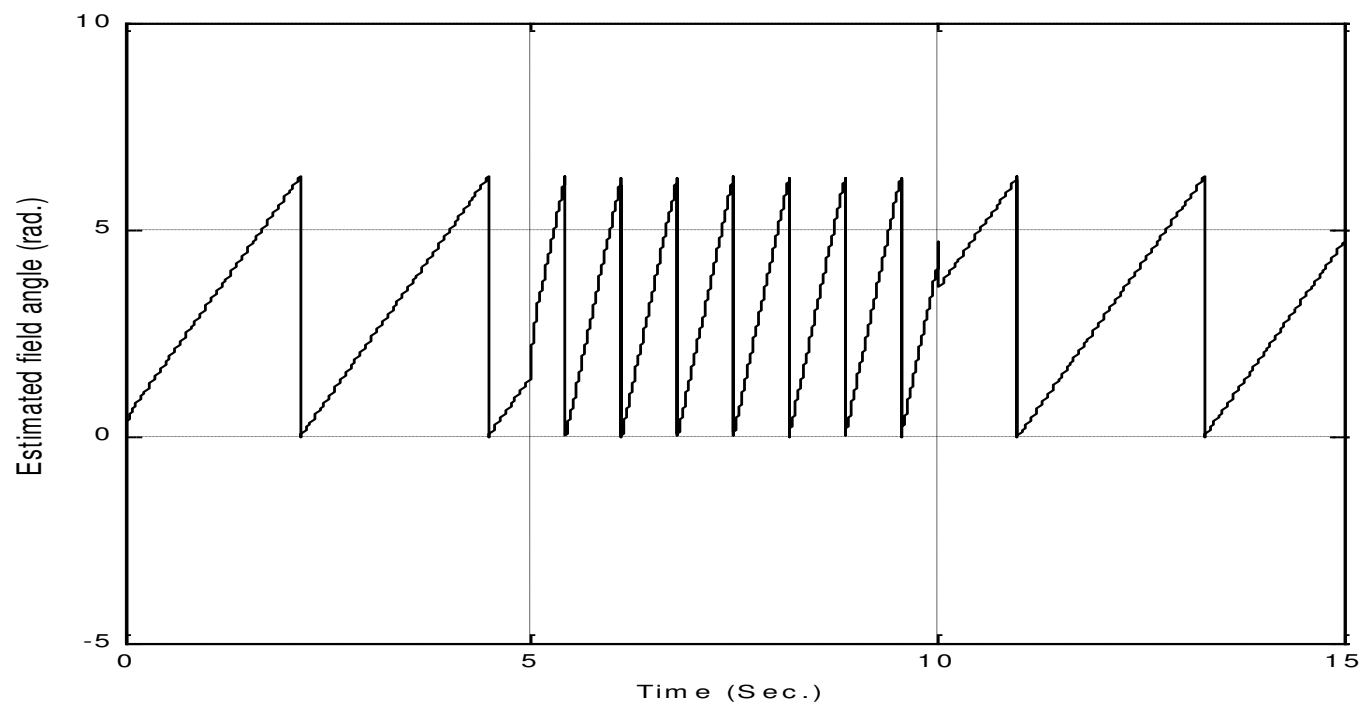

(a)

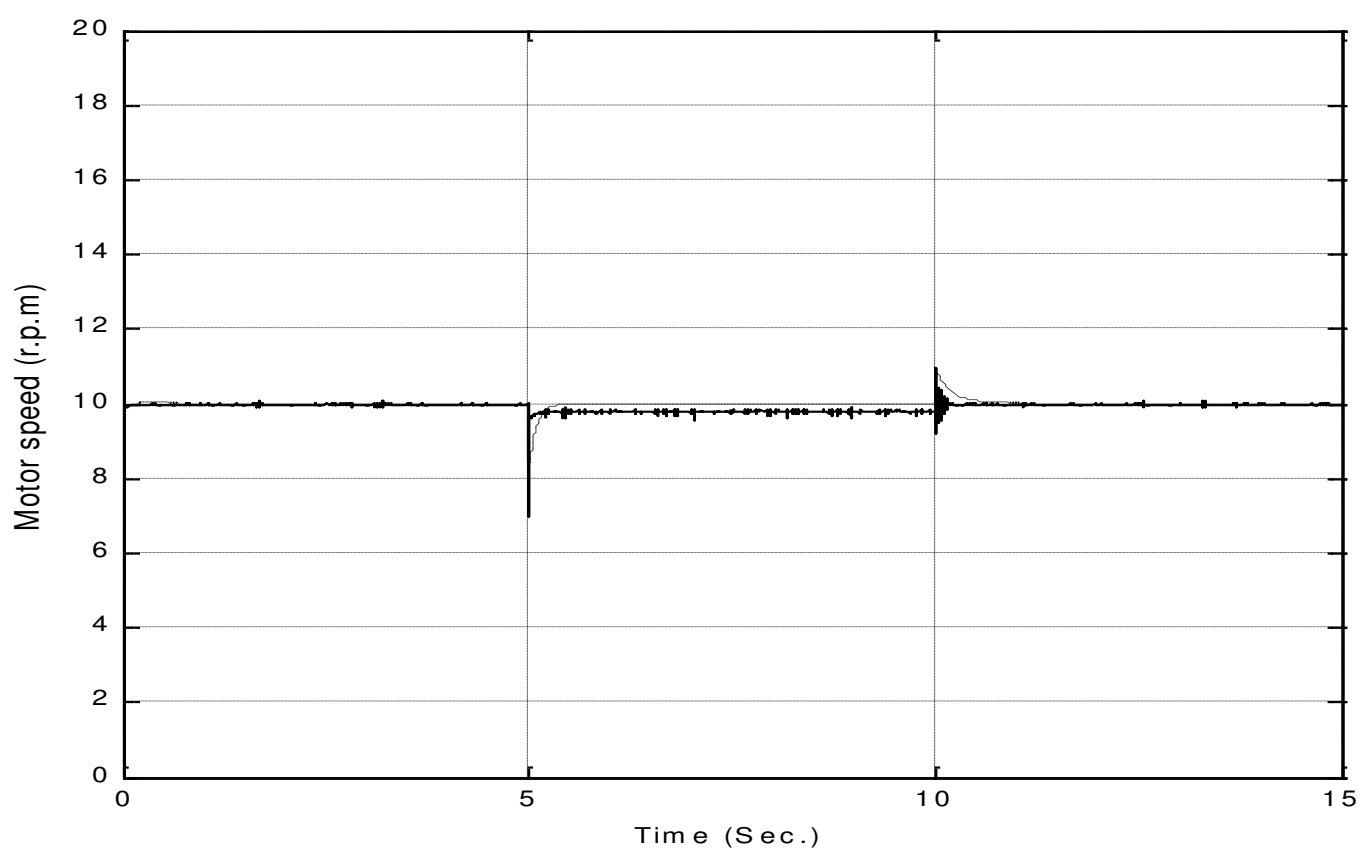

(b) 


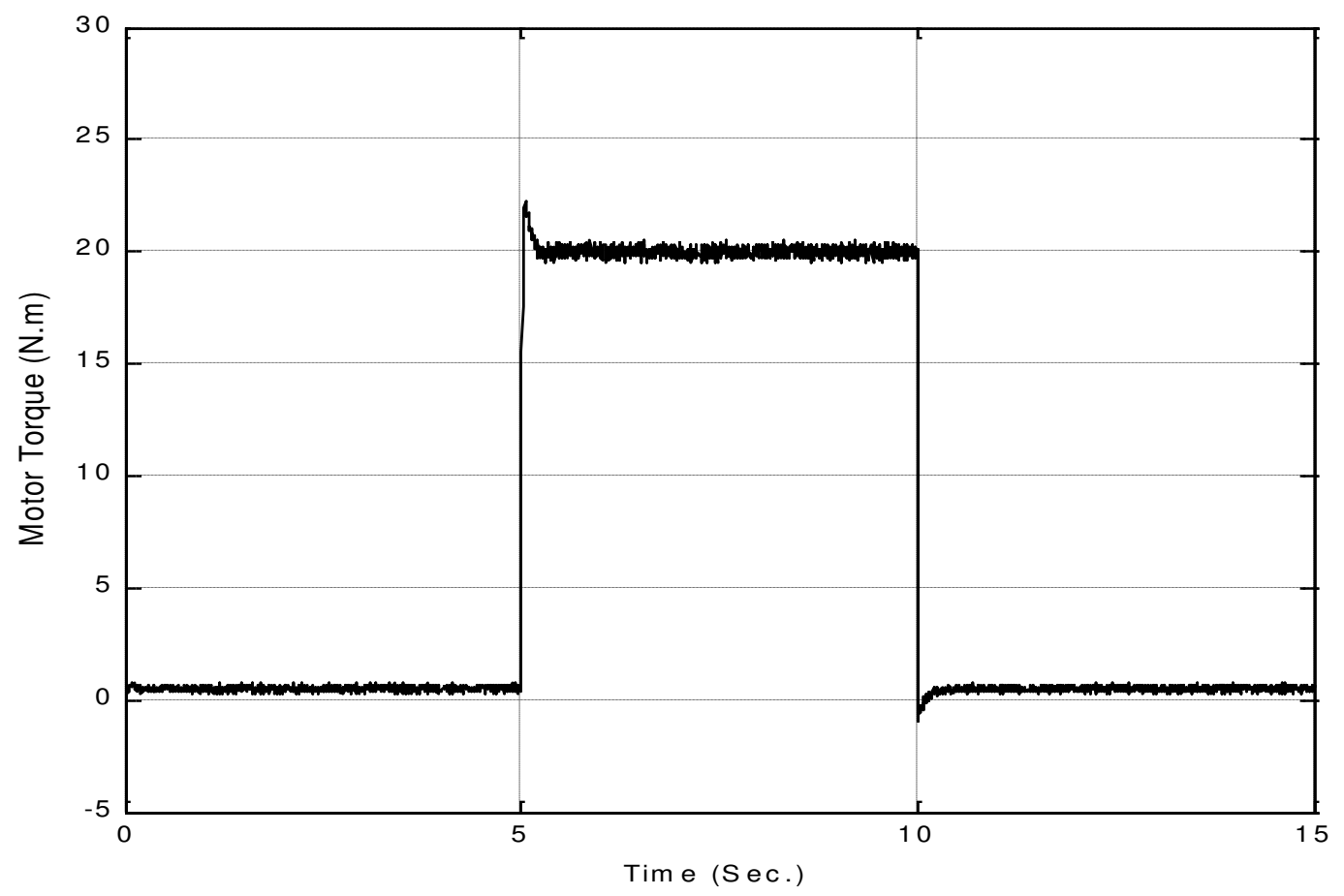

(c)

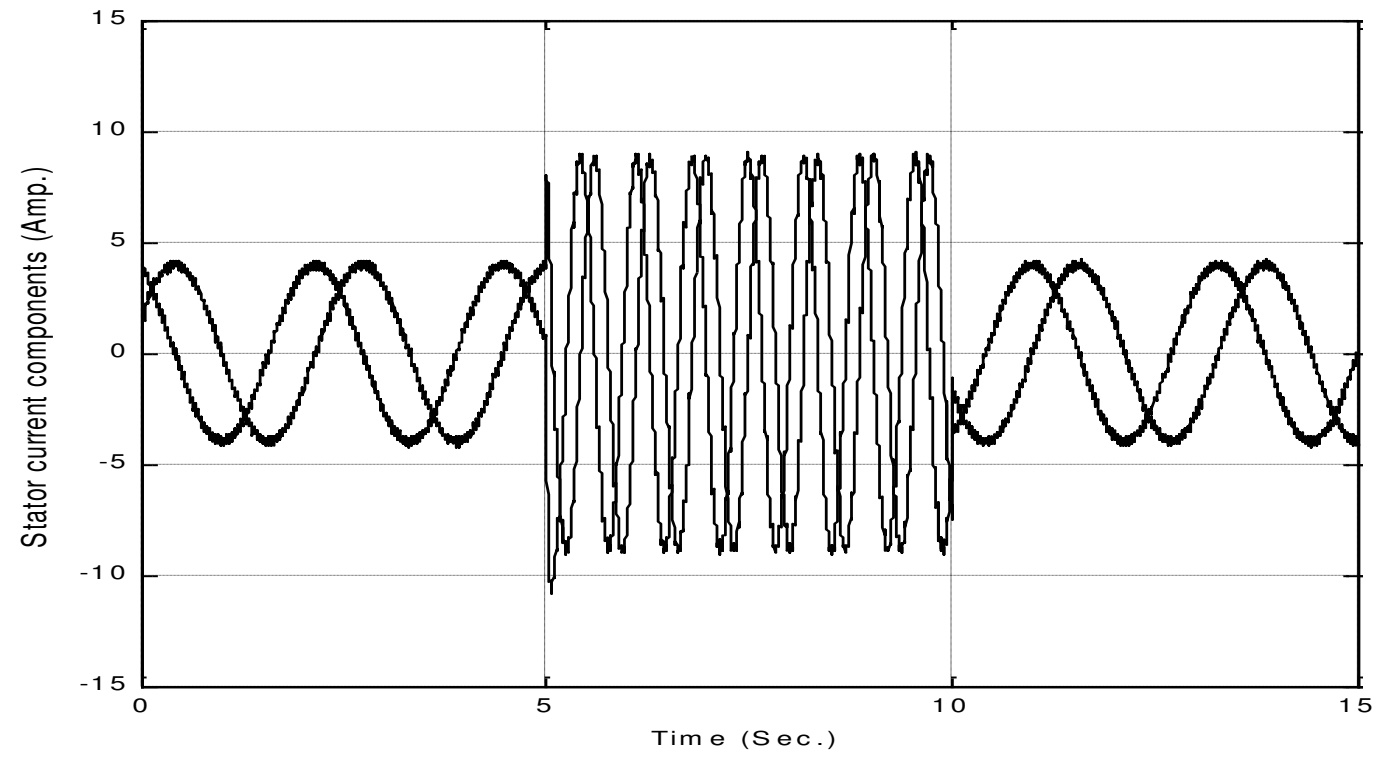

(d) 


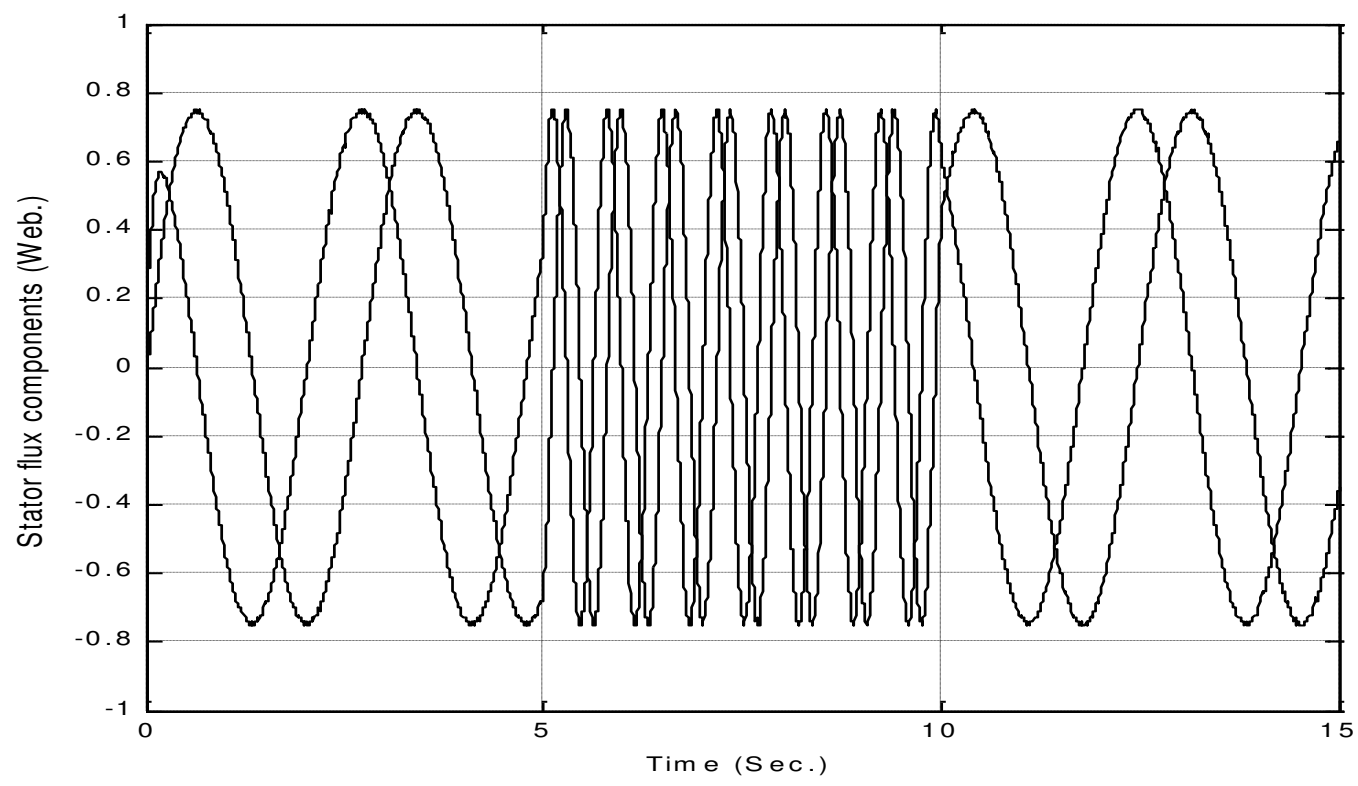

(e)

Figure 3: Simulation results of constant speed operation at $10 \mathrm{rpm}$ with load step changes of rated magnitude applied using the proposed sensorless
(a) estimated field angle
(b) motor speed
(c) motor torque
(d) stator current components
(e) stator flux components

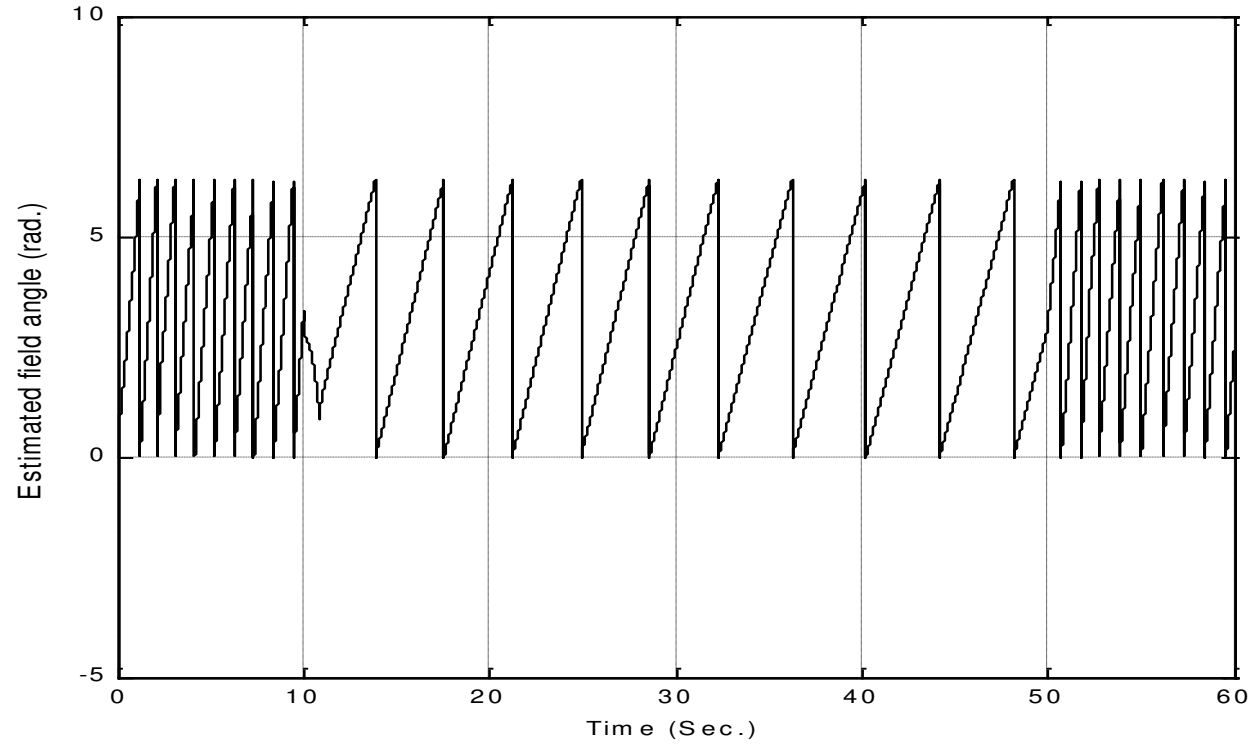

(a) 


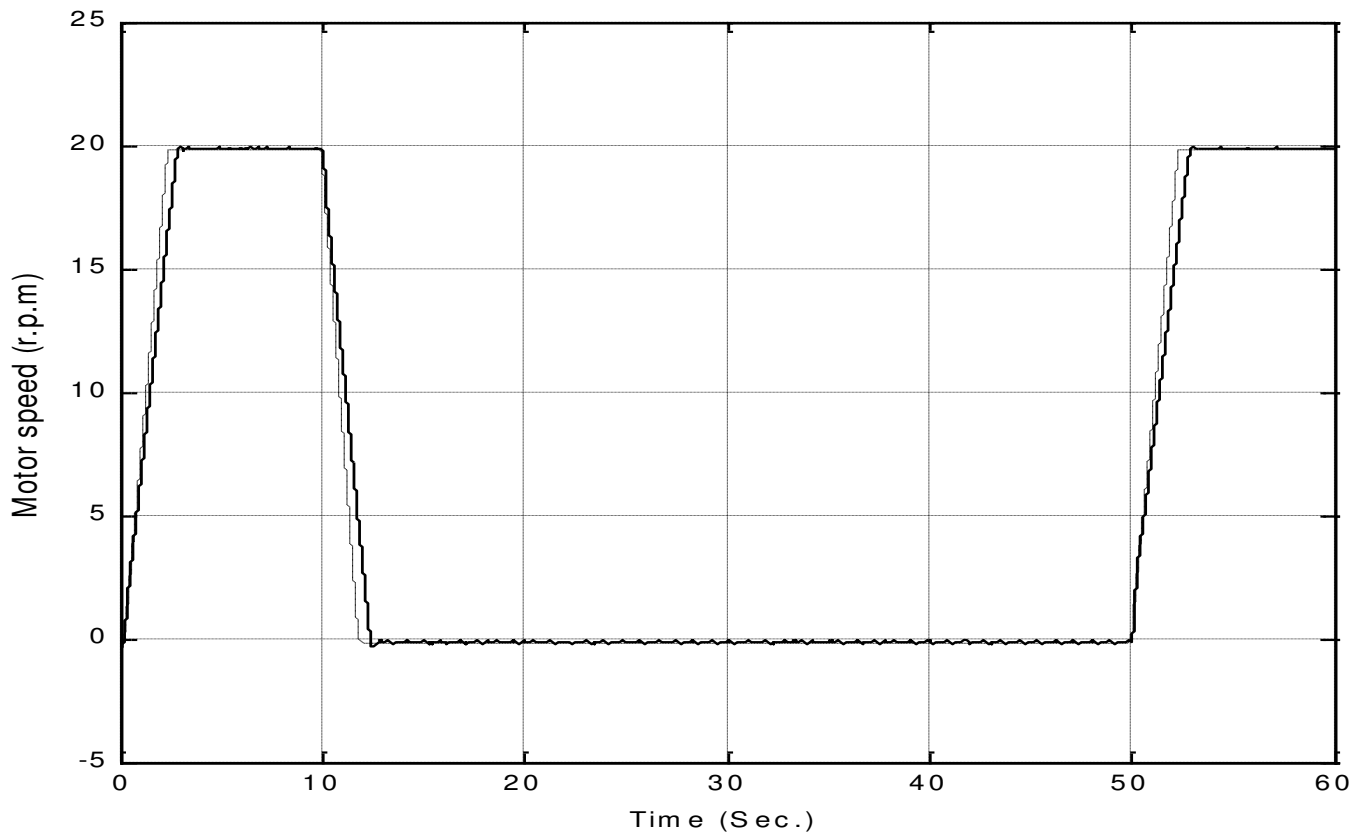

(b)

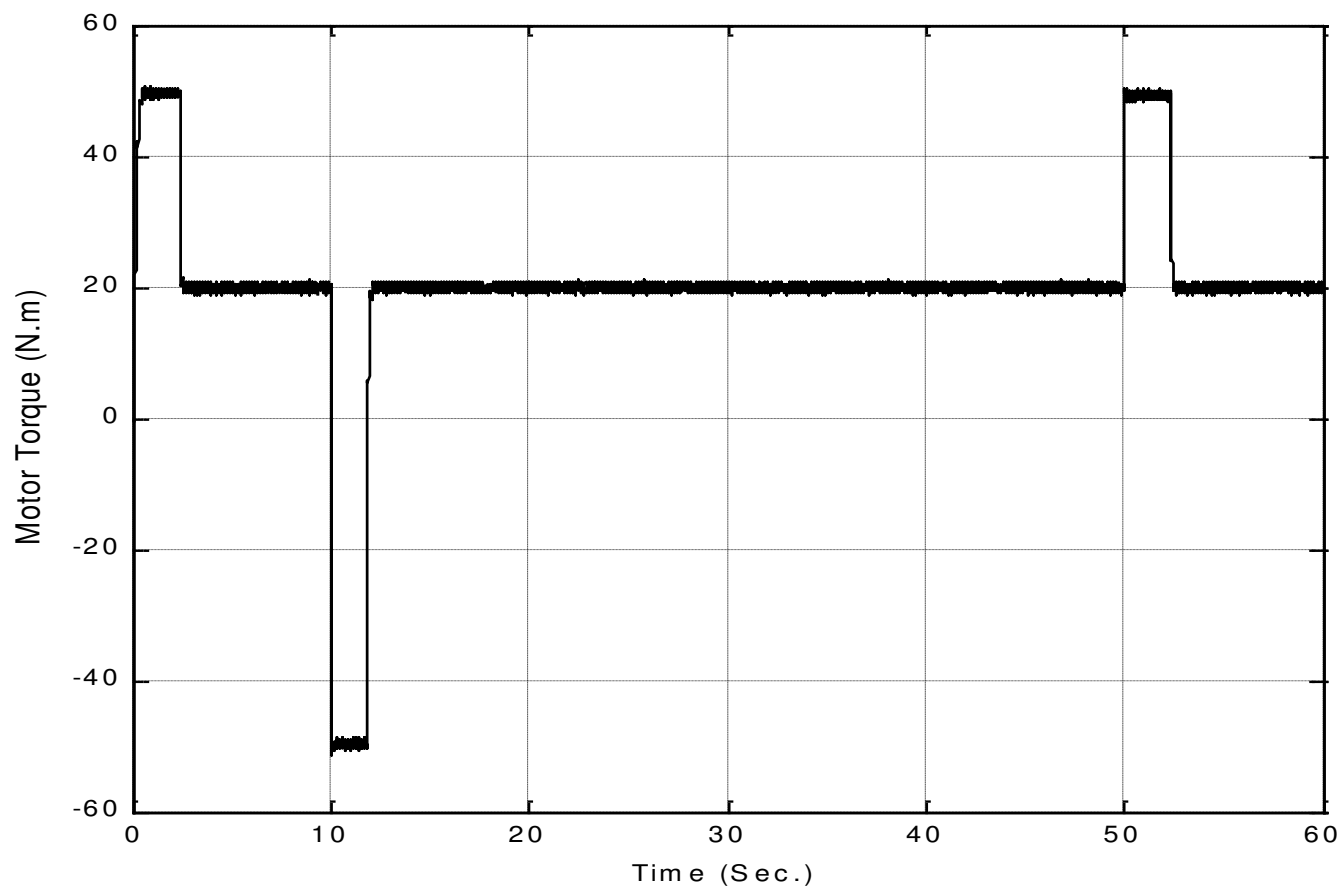

(c) 


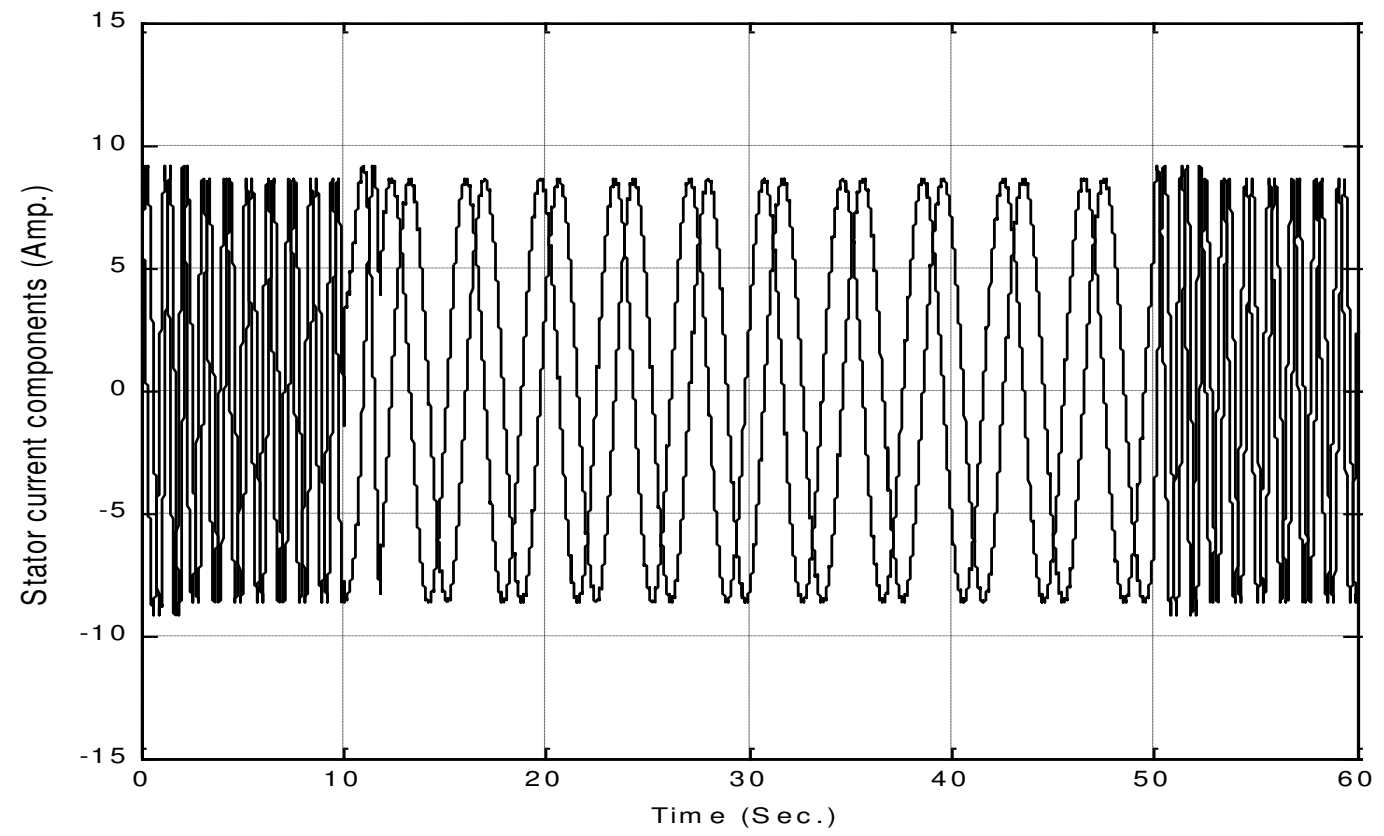

(d)

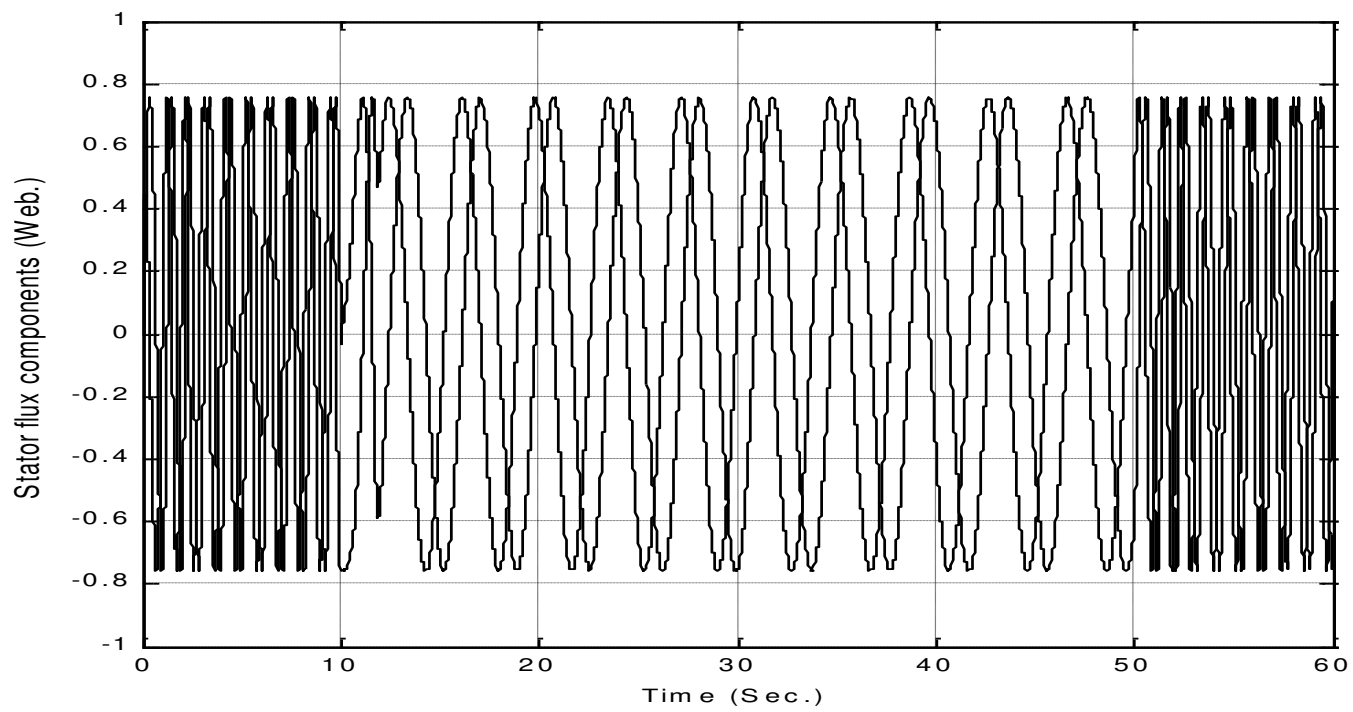

(e)

Figure 4: Simulation results of the zero speed control using the proposed sensorless (loaded motor)
(a) estimated field angle
(b) motor speed
(c) motor torque
(d) stator current components
(e) stator flux components 


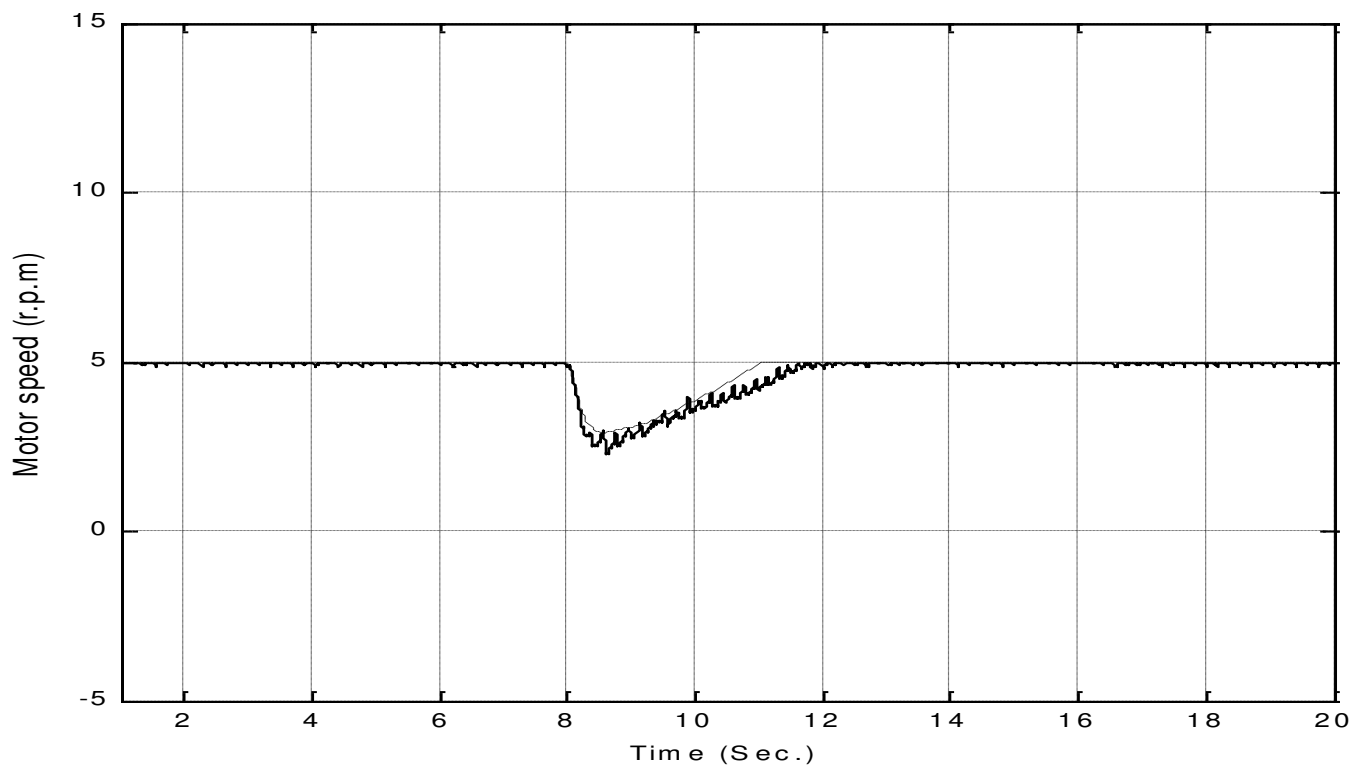

(a)

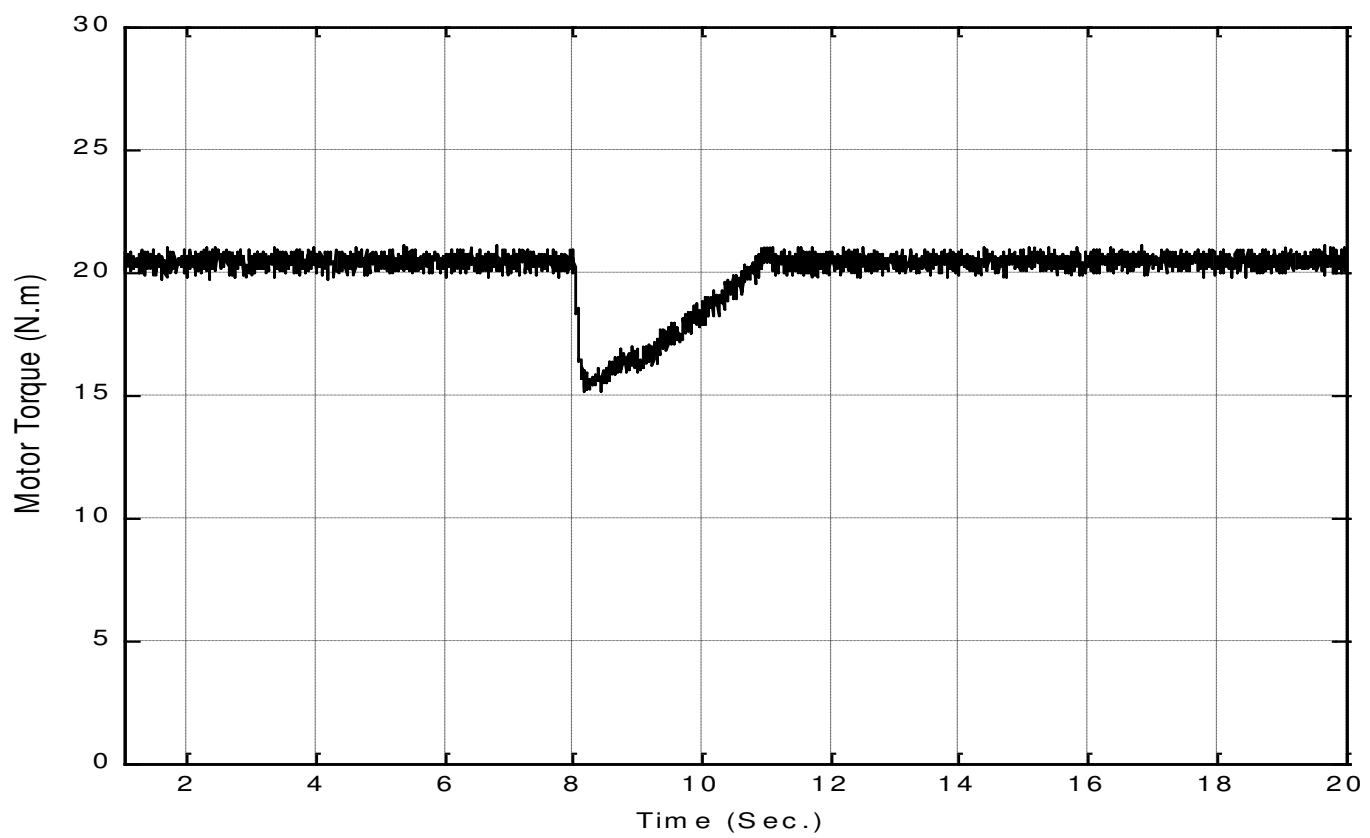

(b) 


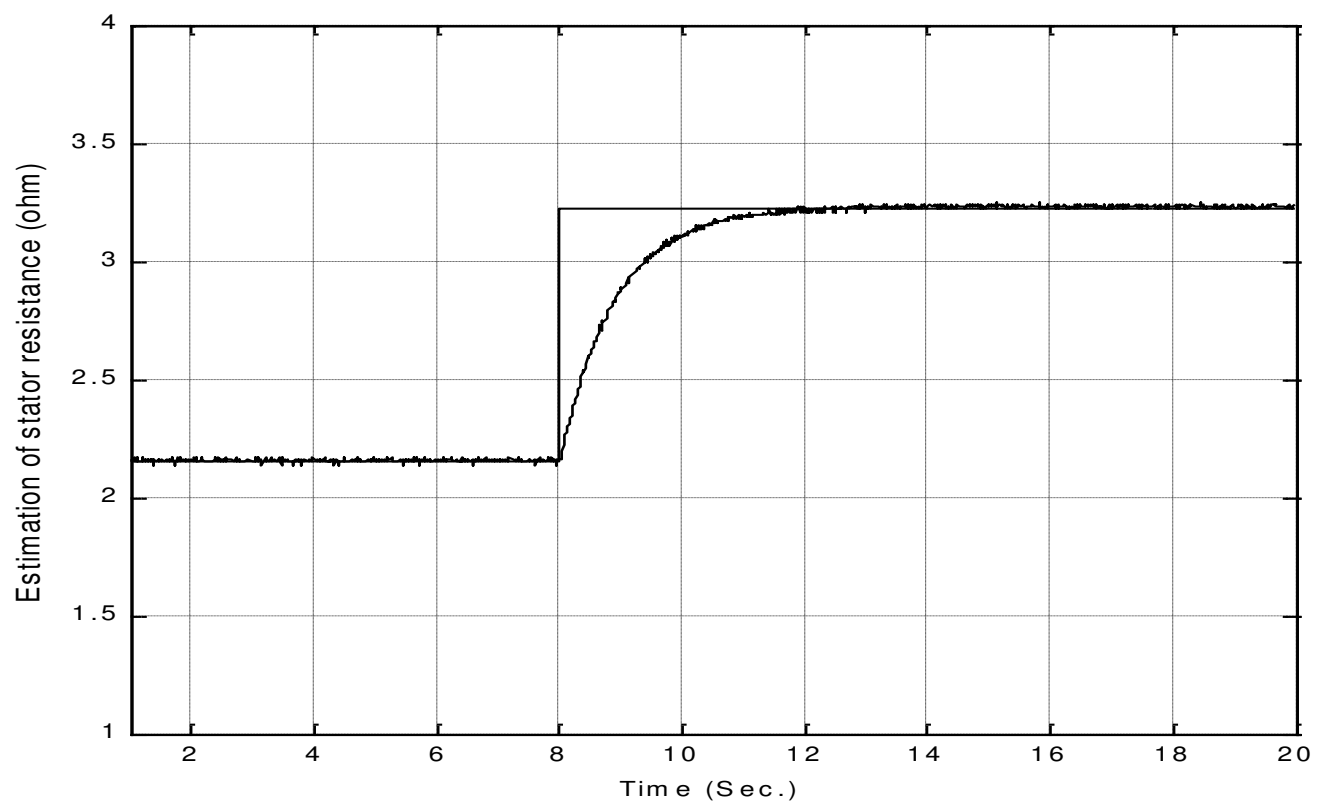

(c)

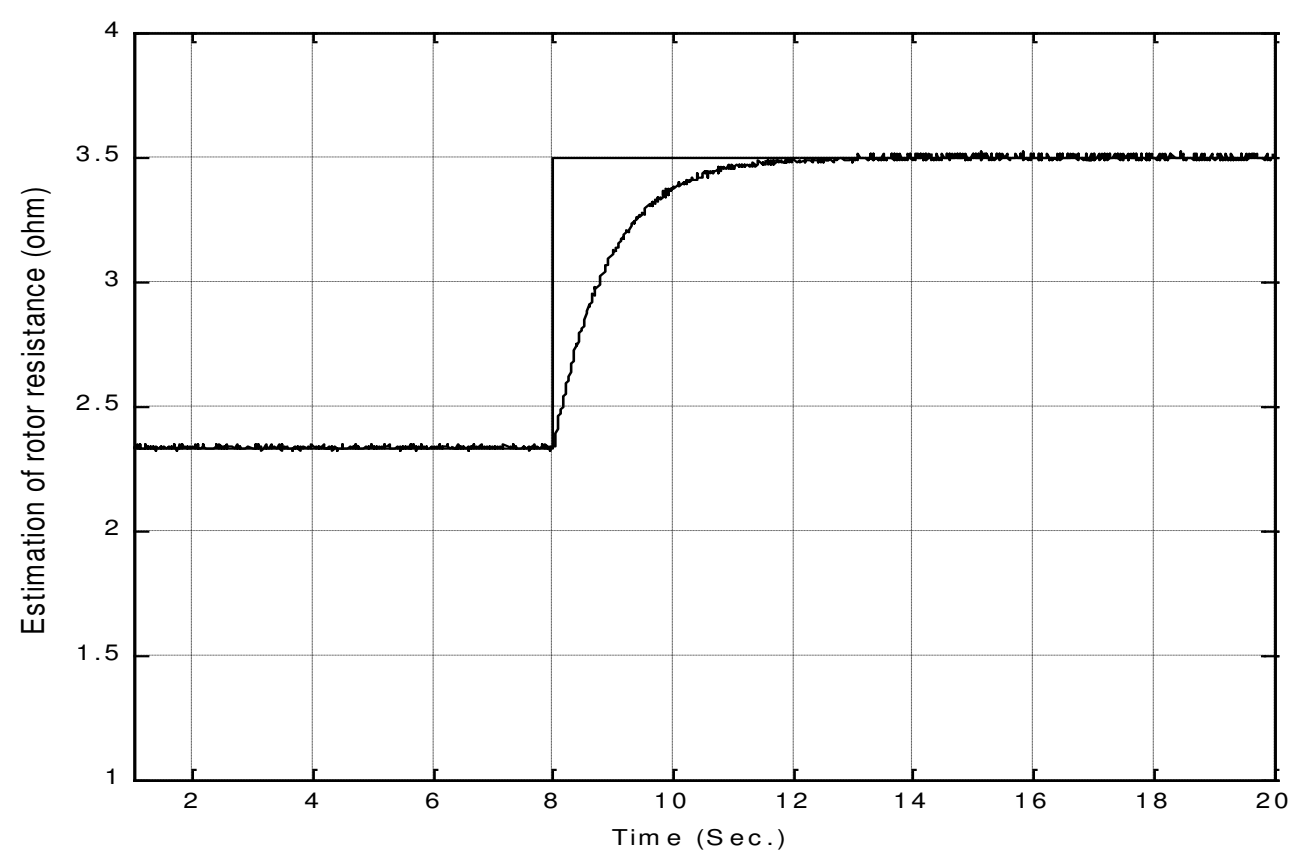

(d)

Figure 5: Estimation of stator and rotor resistances demonstrated by $50 \%$ step increases of the resistances values using the proposed sensorless (loaded motor) $\begin{array}{ll}\text { (a) motor speed } & \text { (b) motor torque }\end{array}$

(c) and (d) estimation of stator and rotor resistances 


\section{CONCLUSION}

This paper has introduced a novel sensorless vector control of induction motor drive. In this drive, the drift components of stator voltage vector is compensated by an estimated offset voltage vector. An effective on-line estimation method for both stator and rotor circuit resistances has been proposed also in this sensorless drive to improve the drive performance at very low-speed. Simulation results are provided to demonstrate smooth stead-state operation and high dynamic performance of the drive system at very low-speed and zero-speed.

The main conclusions are as follows:

1. The motor speed reversal can be estimated with good precision during speed transient and the proposed sensorless exhibits excellent dynamic performance.

2. The transient performance of the proposed sensorless drive is presented when the motor is subjected to a load torque disturbance. Fast and good response of the motor torque is achieved following the application and removal of step-change of the rated load torque

3. Good and stable performance during zero-speed control under full load torque is obtained by the proposed sensorless drive system.

4. The estimation of the motor speed and stator and rotor resistances simultaneously results in accurate speed estimation and good performances are achieved after the estimated stator and rotor resistances track their actual values. Stator and rotor circuit resistances estimation scheme serve to make the machine model more accurate. Therefore, the proposed sensorless drive is robust against the motor parameter variations.

\section{REFERENCES}

[1] C. Schauder, "Adaptive Speed Identification for Vector Control of Induction Motors Without Rotational Transducers," IEEE Trans. Ind. Application, Vol. 28, pp.1054-1061, Sept./Oct. 1992.

[2] H. Kubota, K. Matsuse and T. Nakano, "DSP Based Speed Adaptive Flux Observer of Induction Motor," IEEE Trans . Ind. Application, Vol. 29, pp. 344348, Mar./Apr. 1993.

[3] Y.-R. Kim, S.-K. Sul, and M.-H. Park, "Speed Sensorless Vector Control of Induction Motor Using Extended Kalman Filter," IEEE Trans. Ind. Application, Vol. 30, pp. 1225-1233, Sept./Oct. 1994.

[4] M. W. Degner and R. D. Lorenz, "Position Estimation in Induction Machines Utilizing Rotor Bar Slot Harmonics and Carrier Frequency Signal Injection," in Proc. PCC-Nagaoka, Vol. 1, pp. 69-72, 1997.

[5] K. Rajashekara (Editor)," Sensorless Control of AC Motors", IEEE Press Book, 1996.

[6] J. Hu and B. Wu, "New Integration Algorithms for Estimating Motor Flux over a Wide Speed Range", IEEE Transactions on Power Electronics, Vol. 13, No. 5, pp. 969-977, 1998.

[7] K. Akatsu and A. Kawamura, "Sensorless Very Low-Speed and Zero-Speed Estimations with Online Rotor Resistance Resistance Estimation of Induction 
Motor Without Signal Injection”, IEEE Trans. on Ind. Applications, Vol. 36, No. 3, pp. 764-771, 2000.

[8] R. Marino, S. Peresada, and P. Tomei, "Exponentially Convergent Rotor Resistance Estimation for Induction Motors", IEEE Trans. Ind. Electron., Vol. 42, pp. 508-515, Oct. 1995.

[9] D. J. Atkinson, J. W. Finch, and P. P. Acarnley, "Estimation of Rotor Resistance in Induction Motor", Proc. IEE-Elect. Power Application, Vol. 143, No. 1, pp. 87-94, Jan. 1996.

[10] A. Garcia-Cerrada and J. L. Zamora, "On-Line Rotor-Resistance Estimation for Induction Motor", in Proc. EPE'97, Vol. 1, Trondheim, Norway, pp. 542-547, Sept. 1997.

[11] R. Beguanne and M. E. H. Benbouzid, "Induction Motors Thermal Monitoring by Means of Rotor Resistance Identification", IEEE Trans. Energy Conv., Vol. 14, pp. 566-570, Sept. 1999.

[12] S. Shinnaka, "A Unified Analysis on Simultaneous Identification of Velocity and Rotor Resistance of Induction Motor", (in Japanese), Trans. Inst. Elect. Jpn., Vol. 113-d, No. 12, pp. 1483-1484, 1993.

[13] I. Miyashita, H. Fujita, and Y. Ohmori, "Speed sensorless instantaneous vector control with identification of secondary resistance", in Conf. Rec. IEEE-IAS Annual Meeting, p.p. E130-E135, 1991.

[14] J. Jiang and J. Holtz, "High Dynamic Speed Sensorless ac Drive With On-line Model Parameter Tuning for Steady-state Accuracy”, IEEE Trans. Ind. Electron. Vol. 44, p.p. 240-246, Apr. 1997.

[15] H. Kubota and K. Matsuse, "Speed Sensorless Field Oriented Control of Induction Motor with Rotor Resistance Adaptation", in Conf. Rec. IEEE-IAS Annual Meeting, p.p. 414-418, 1993.

[16] I.-J. Ha and S.-H. Lee, "An Online Identification Method for both Stator and Rotor Resistances of Induction Motors Without Rotational Transducers", IEEE Trans. on Industrial Electronics, Vol. No. 4. 2000, pp. 842-853.

[17] J. Campbell and M. Sumner, "Practical Sensorless Induction Motor Drive Employing an Artificial Neural Network for Online Parameter Adaptation", IEE Proc. Electr. Appl. , Vol. 149, No. 4, PP. 225-260, July 2002.

[18] M. Hinkkanen, V.-M. Lepp, and J. Luomi "Flux Observer Enhanced With Lowfrequency Signal injection allowing Sensorless Zero-frequency Operation of induction Motors", Conference Record of the 2003 IEEE Industry Applications Conference (IAS 2003). Salt Lake City, UT, USA, 12-16 October 2003, Pages 1150-1156, 2003.

[19] S. M. Malik, Elbuluk and D. S. Zinger, " PI and Estimators for Tuning the Stator Resistance in Direct Torque of Induction Machines", IEEE Tran. On Power Electronics, Vol. 1, No. 2, March, 1998. 


\section{تقييم السرعة والثوابت لمحرك حثي يعمل عند السرعات البطيئة بنظام

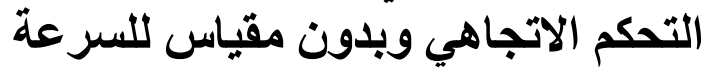

يقدم هذا البحث نظام جديد للتحكم الاتجاهي لمحرك حثي بدون مقياس للسر عة. في هذا النظام تم معادلة تأثثر مركبة جهد الانحر اف (drift voltage) في متجـه جهد

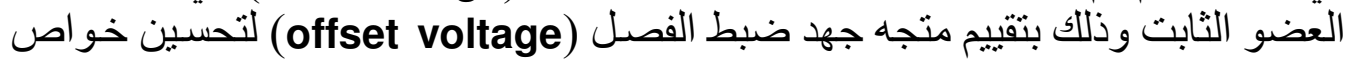

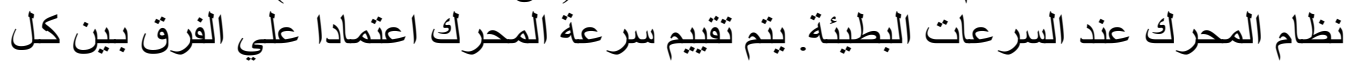

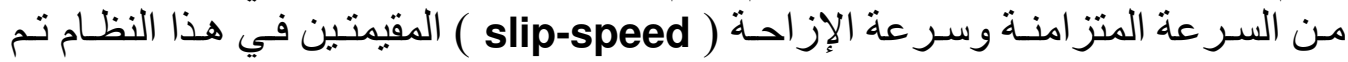

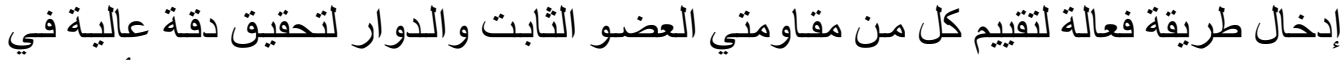

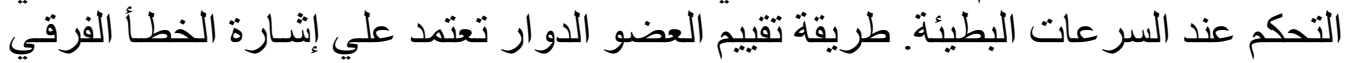

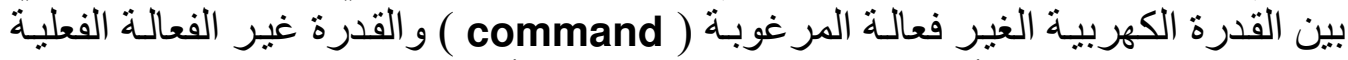
(actual) المرغوب (command) و التيار المقاس لتقبيم التغير في مقاومة العضو الثنابت.

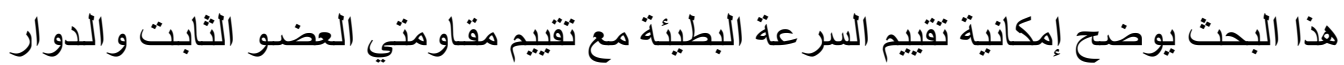
لتحقيق التحكم الدقيق عند السرعة المنعدمة (الصفرية) في حالة وجود الحملية الحمل الكامل. و النتائج النظرية معروضة لكي توضح التشغيل الناعم في حالة الاستقر ار وكذلك الأداء الديناميكي العالي لنظام المحرك عند السر عات البطيئة و المنعدمة (الصفرية). 